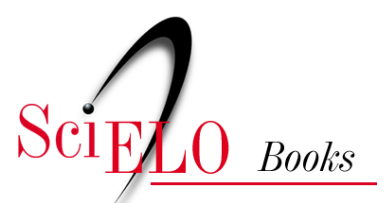

\title{
Capítulo 8. Perfil demográfico socioeconômico das pessoas que se autodeclararam 'Indígenas' nos censos demográficos de 1991 e 2000
}

\author{
Nilza de Oliveira M. Pereira \\ Ricardo Ventura Santos \\ Marta Maria Azevedo
}

\section{SciELO Books / SciELO Livros / SciELO Libros}

PEREIRA, N.O.M., SANTOS, R.V., and AZEVEDO, M.M. Perfil demográfico socioeconômico das pessoas que se autodeclararam 'Indígenas' nos censos demográficos de 1991 e 2000. In: PAGLIARO, H., AZEVEDO, MM., and SANTOS, RV., comps. Demografia dos povos indígenas no Brasil [online]. Rio de Janeiro: Editora FIOCRUZ, 2005, pp. 155-166. Saúde dos Povos Índigenas collection. ISBN: 978-857541-254-1. https://doi.org/10.7476/9788575412541.0009.

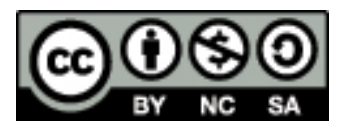

All the contents of this work, except where otherwise noted, is licensed under a Creative Commons Attribution-Non Commercial-ShareAlike 3.0 Unported.

Todo o conteúdo deste trabalho, exceto quando houver ressalva, é publicado sob a licença Creative Commons Atribuição - Uso Não Comercial - Partilha nos Mesmos Termos 3.0 Não adaptada. 


\section{Perfil Demográfico e Socioeconômico das Pessoas que se Autodeclararam 'Indígenas' nos Censos Demográficos de 1991 e 2000}

\section{Introdução}

Há uma notável carência de dados demográficos sobre as populações indígenas no Brasil. Em face da diversidade histórica, social e cultural dos povos indígenas, que somam mais de 200 etnias, falantes de 180 línguas diferentes, é praticamente nulo o que se conhece não somente acerca de sua estrutura populacional, como também dos níveis e padrões de fecundidade, mortalidade e migração, dentre outros aspectos da dinâmica demográfica (Silva, 1994; Ricardo, 1996; Azevedo, 2000; Santos G Coimbra Jr., 2003; Pagliaro et al., neste volume). Se os dados são escassos para os indígenas residentes em terras oficialmente reconhecidas pelo Estado brasileiro, são ainda menos conhecidas as características demográficas dos que vivem em áreas urbanas.

Nos últimos anos, nota-se a consolidação de diversas iniciativas voltadas para reverter o quadro de carência de dados demográficos sobre os povos indígenas no Brasil (ver Pagliaro et al., neste volume). Como exemplos podem ser citados o aumento no número de pesquisas em comunidades específicas e a consolidação de redes de pesquisadores voltados para o estudo da demografia indígena (como o Comitê de Demografia dos Povos Indígenas da Associação Brasileira de Estudos Populacionais - Abep). Outra iniciativa de grande relevância foi a inclusão da opção 'indígena' no quesito cor ou raça dos censos decenais a partir de 1991.

A metodologia para classificação da população indígena utilizada nos Censos Demográficos de 1991 e 2000 foi a autodeclaração, aplicando-se tanto aos indivíduos que nos anos dos censos habitavam as Terras Indígenas, quanto aos que viviam fora dessas áreas (IBGE, 1991, 2000, 2003).

O objetivo deste capítulo é apresentar um perfil demográfico e socioeconômico das pessoas que se declararam 'indígenas' ${ }^{1}$ nos Censos de 1991 e 2000. De antemão, é importante frisar que, para fins deste trabalho, a categoria 'indígena' do IBGE (Instituto Brasileiro de Geografia e Estatística) não é tomada 
como sinônimo ou substituta de 'povos indígenas', de 'grupos indígenas' ou de 'população indígena', nos moldes que predomina na literatura antropológica especializada. Isso porque, por meio de seu sistema de coleta de informações, os censos vêm captando diferentes categorias sociológicas, duas das quais são as seguintes: povos indígenas enquanto totalidades sociológicas distintas, definidos pela convenção 169 da OIT (Organização Internacional do Trabalho), ou seja, povos que se diferenciam da coletividade nacional por seus usos, costumes e tradições; e, por outro lado, conjuntos de pessoas que se reconhecem como descendentes de índios (ou índio-descendente), mas que não sabem a que povo ou etnia pertenciam seus ancestrais indígenas. Ao traçar um perfil dos que se autodeclararam 'indígenas' nos censos, o intuito é contribuir para sistematizar e divulgar o que se constitui em uma importante base de dados pertinente a essa população, até agora muito pouco conhecida do ponto de vista demográfico, com objetivo de inclusive aprimorar a formulação do quesito cor/raça/etnia nos próximos censos e em outros levantamentos demográficos.

\section{Características demográficas}

Em 1991, 294 mil pessoas se declararam 'indígenas' (0,2\% da população total do país), enquanto que em 2000 o montante foi de $734 \mathrm{mil}$ (0,4\% da população total). Portanto, um aspecto de grande relevância que emerge da comparação dos dois censos é o crescimento expressivo no número de indivíduos que se autodeclararam como 'indígenas'.

Houve não somente um aumento substancial no período, como também uma alteração na proporção dos 'indígenas' segundo tipo de situação de domicílio. Segundo o Censo de 1991, 24,1\% viviam em áreas urbanas e 75,9\% em área rural. Já em 2000 a distribuição foi de 52,2\% em área urbana e 47,8\% em área rural.

Tanto para o Censo Demográfico de 1991 quanto para o de 2000, há diferenças significativas na estrutura por sexo e idade dos 'indígenas' segundo situação do domicílio (Figuras 1, 2 e 3). Os residentes em áreas urbanas acompanham o padrão da composição por sexo e idade da população brasileira, que apresentou como característica baixa fecundidade e mortalidade, bem como uma razão de dependência baixa e idade mediana alta (Figura 2). Já para os 'indígenas' residentes na,área rural, o comportamento piramidal é representativo de regimes populacionais com alta natalidade e mortalidade (Figura 3), que são também os padrões geralmente observados em estudos demográficos de povos indígenas específicos conduzidos por antropólogos e demógrafos (Early G Peters, 1990; Azevedo, 2000; Souza G Santos, 2001; Coimbra Jr. et al., 2002; Pagliaro, 2002; ver também Pagliaro, Santos et al., Azevedo, Teixeira e Brasil, neste volume). 
Figura 1 - Composição da população residente que se autodeclarou indígenatoral pur sexo e idade. Brasil - 1991/2000

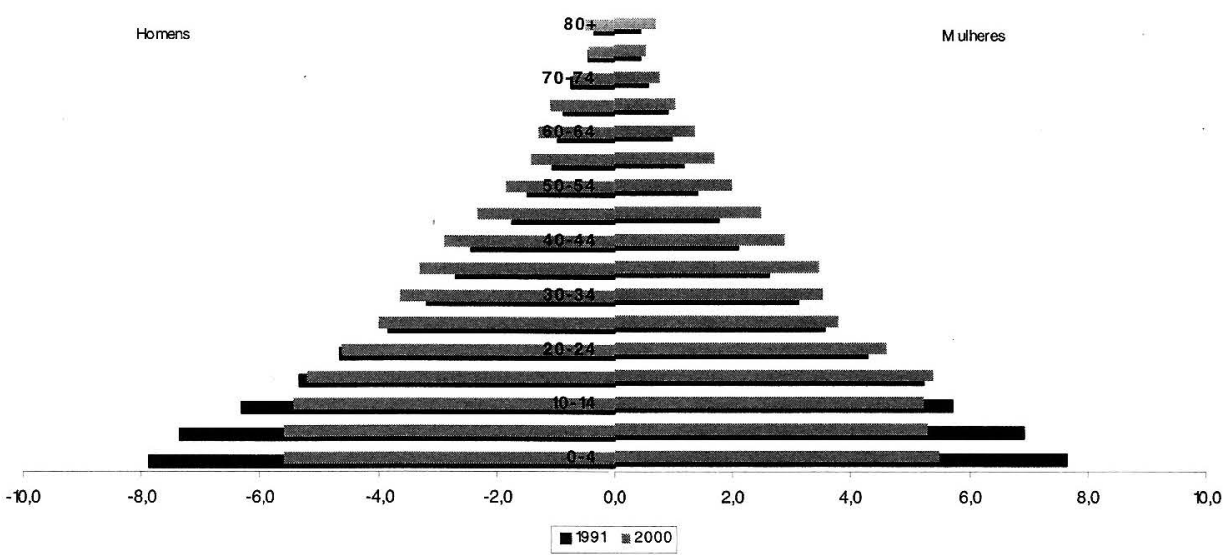

Figura 2 - Composição da população residente que se autodeclarou indígena urbana, por sexo e idade. Brasil - 1991/2000

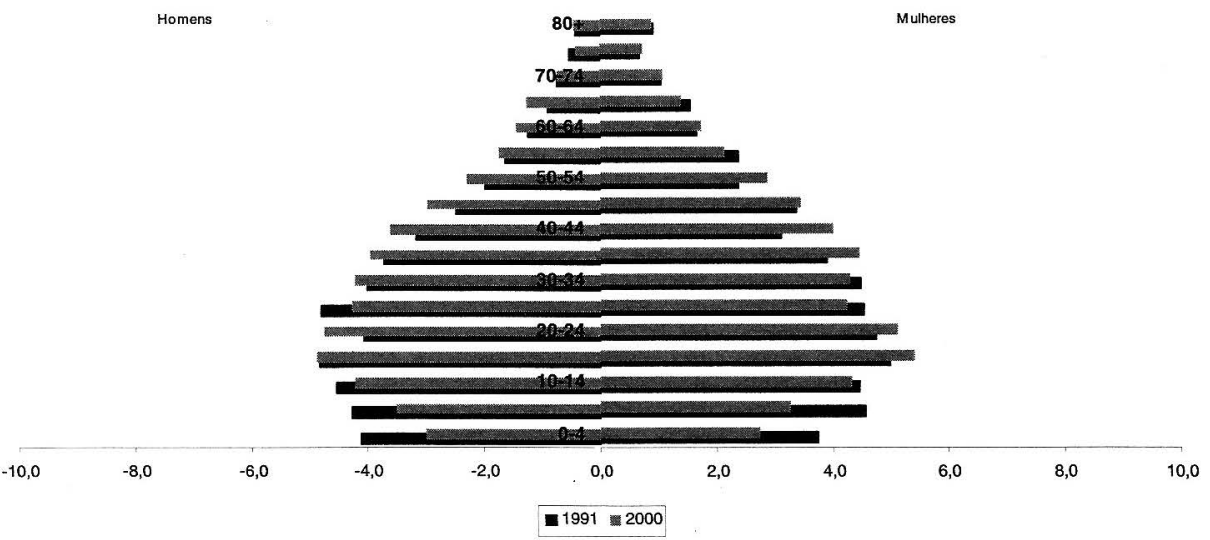

Figura 3 - Composição da população residente que se autodeclarou indígena rural, por sexo e idade. Brasil - 1991/2000

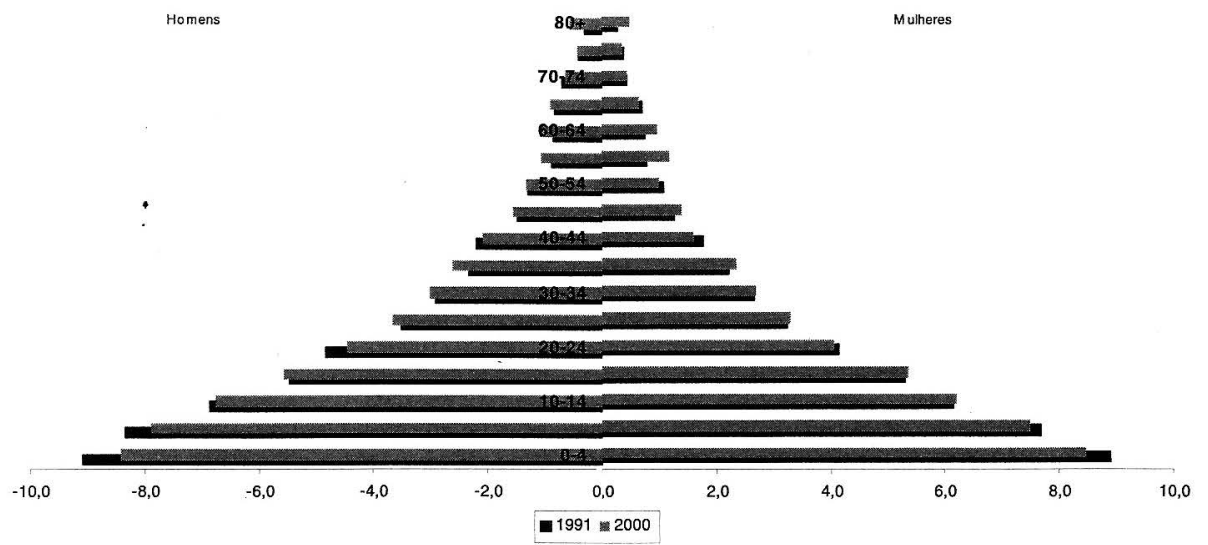


A idade mediana dos 'indígenas' revelada pelo Censo Demográfico 2000 foi 23,2 anos (22,9 anos para homens e 23,5 anos para mulheres), valor superior ao detectado pelo Censo Demográfico de 1991, que foi de 18,4 anos (18,2 anos para homens e 18,6 anos para mulheres). É particularmente expressiva a diferença das medianas de idade entre 'indígenas' rurais e urbanos tanto em 1991 (16,2 vs. 28,2 anos) como em 2000 (16,8 vs. 30,1 anos).

Segundo o Censo Demográfico de 1991, para os 'indígenas', as proporções de indivíduos de 0 a 14 anos de idade e de adultos ( 15 a 64 anos de idade) eram semelhantes (41,8\% e 53,4\%, respectivamente). Já os idosos (65 anos ou mais) representavam somente $4,7 \%$ da população total. Em 2000, a participação relativa do contingente de crianças e adolescentes declinou e a contribuição dos adultos cresceu (Figura 4). Assim, as proporções de crianças e adolescentes ( 0 a 14 anos de idade) e de adultos (15 a 64 anos de idade) passaram a ser de 32,6\% e 61,6\%, respectivamente. Considerando situação de moradia, a proporção de crianças e adolescentes na área rural (45,2\%) foi duas vezes maior que na área urbana (21,1\%). Para os com 65 anos ou mais, o padrão mostrou-se o inverso, com uma maior proporção $(7,0 \%)$ na área urbana, com a rural apresentando somente $4,4 \%$.

Figura 4 - Proporção da população que se autodeclarou indígena por situação do domicílio, segundo os grupos de idade. Brasil - 2000

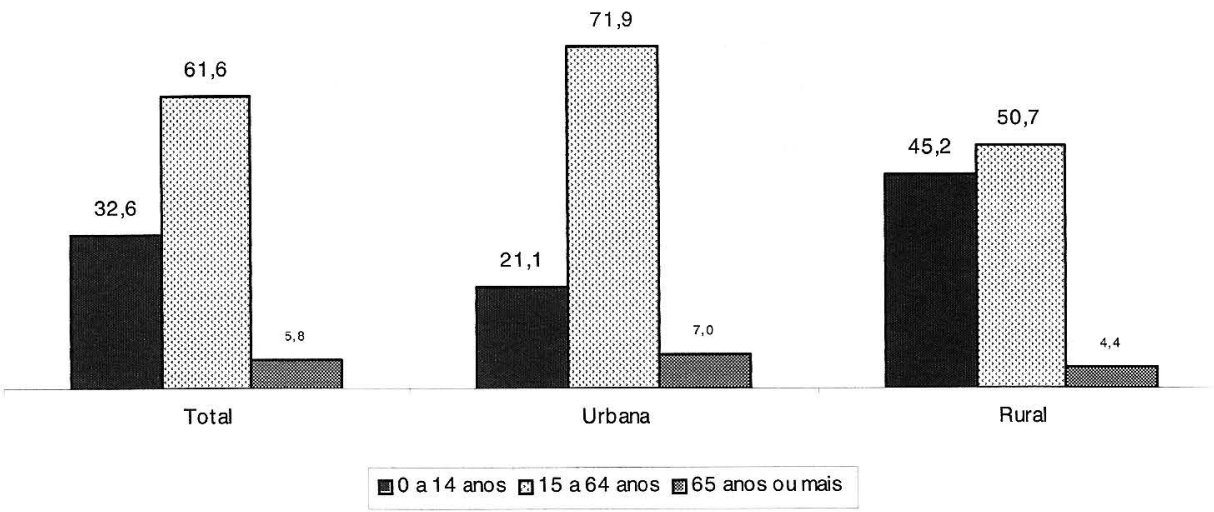

Mesmo que tenha decrescido o número de jovens segundo o Censo Demográfico 2000 se comparado ao de 1991, um aspecto que permaneceu foi que os 'indígenas' conformam uma população bastante jovem. Assim, segundo os resultados de 2000 , mais da metade (52\%) tinha até 24 anos de idade (41\% na área urbana e 65\% na área rural).

Segundo os dados do Censo Demográfico 2000, a proporção de 'indígenas' com até 24 anos tende a ser menor nas regiões Sul e Sudeste, e de certo modo 
também na Nordeste. As regiões Centro-Oeste e Norte concentram um contingente indígena comparativamente mais jovem.

Essas diferenças marcantes entre o perfil etário da população 'indígena' rural e urbana provavelmente se devem justamente à diferença entre os perfis demográficos dos povos indígenas residentes nas Terras Indígenas (considerados pelos censos como rurais) e os índios descendentes das áreas urbanas, já com um perfil demográfico mais próximo da população brasileira em geral.

No Brasil, a tendência histórica quanto às razões de sexo é de predominância feminina para a população total. Quanto à situação de domicílio, esse padrão se verifica também para a área urbana, com uma inversão no contexto rural, no qual há mais homens do que mulheres. Para os 'indígenas', o Censo Demográfico 2000 revelou um equilíbrio entre homens e mulheres (Figura 5). No tocante à área urbana e rural, observa-se um quadro semelhante àquele da população brasileira como um todo.

Figura 5 - Razão de sexo da população que se autodeclarou 'indígena', segundo a situação do domicílio. Brasil - 1991-2000

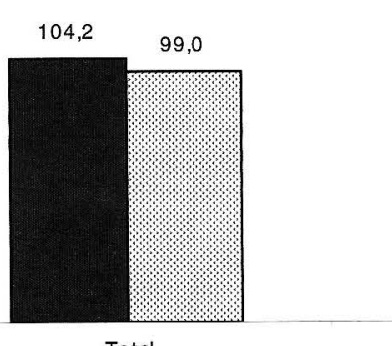

Total

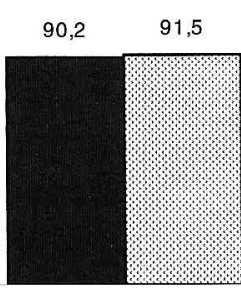

Urbana

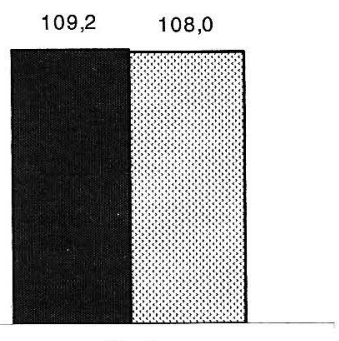

Rural

ఐ1991문 2000

Conforme já referido, os resultados do Censo Demográfico 2000 revelaram que o contingente 'indígena' apresentou um crescimento significativo em relação ao Censo Demográfico de 1991, da ordem de 10,8\% ao ano. O aumento foi mais significativo na área urbana (20,8\% ao ano) que na rural (5,2\% ao ano) (Figura 6). A região geográfica que apresentou o maior crescimento foi a Sudeste $(20,5 \%$ ao ano); o menor ficou com a Norte $(6,2 \%$ ao ano). Isto talvez ocorra graças ao aumento de autodeclaração de índio-descendentes nas áreas urbanas das regiões Sudeste, Centro-Oeste e Nordeste, principalmente. Nas áreas rurais, os autodeclarados 'indígenas' são pertencentes aos povos; logo, não deve ter havido um grande aumento na autodeclaração, mas sim um aumento populacional por causa do crescimento vegetativo destes povos. Não há diferenciais acentuados nas taxas médias 
geométricas de crescimento anual de homens e mulheres, com ambos os sexos acompanhando a tendência da população 'indígena' total.

Figura 6 - Taxa média geométrica de crescimento anual da população residente que se autodeclarou indígena por situação do domicílio, segundo as Grandes Regiões. Brasil - 1991-2000

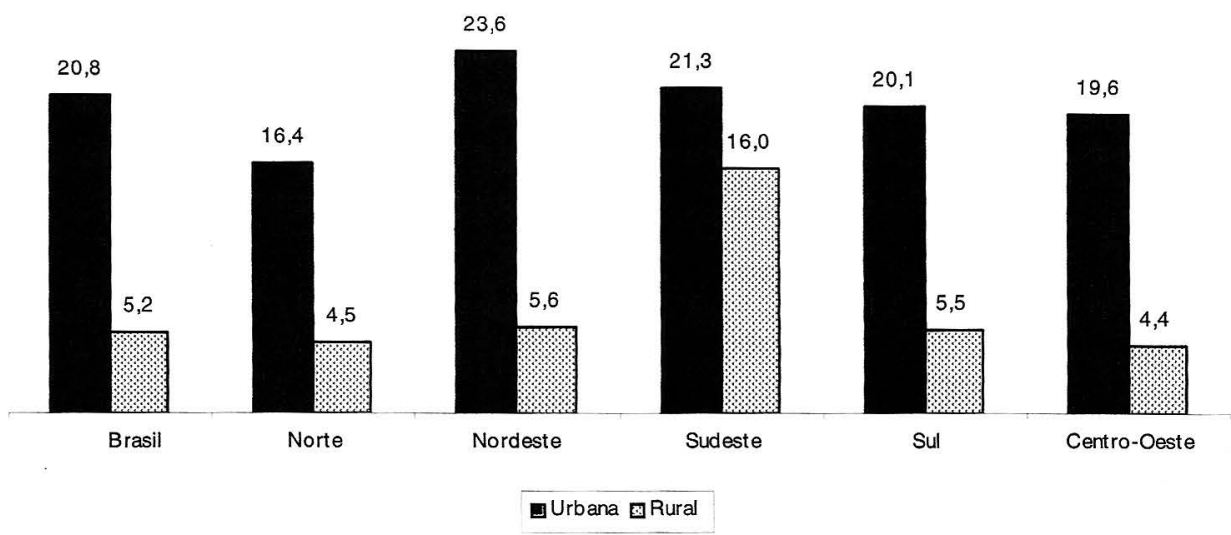

Componentes da dinâmica demográfica

As informações provenientes do Censo Demográfico de 1991 não possibilitaram boas estimativas do nível de fecundidade das mulheres que se autodeclararam como 'indígenas'. Já para o Censo Demográfico 2000, as informações foram mais robustas, o que tornou possível calcular a taxa de fecundidade total das 'indígenas' de 15 a 49 anos, que foi de 3,9 filhos por mulher ( 2,7 filhos por mulher para a área urbana e 6,0 filhos por mulher para a área rural).

Quanto a outros parâmetros relativos ao comportamento reprodutivo das mulheres, calculados com as informações relativas a 2000, a taxa bruta de natalidade dos 'indígenas' foi de 32,7 por mil, com diferenças importantes entre as áreas urbanas e rurais (25,4 e 41, 9 por mil, respectivamente). A taxa geral de fecundidade em 2000 era de 12,5 , com o valor para a área rural $(20,2)$ mais que o dobro daquele da área urbana $(8,2)$.

Quanto aos resultados relativos à migração, em 2000 foram recenseadas 103.483 'indígenas' residentes em Unidades da Federação diferentes daquelas onde nasceram. Foi no Sudeste, região na qual houve o maior incremento de 'indígenas', que se verificou também o mais elevado fluxo migratório, sobretudo para Rio de Janeiro e para São Paulo (Figura 7). Tal observação levanta a possibilidade de que o aumento das pessoas que se autodeclararam 'indígenas' nesses e em outros estados, 
de 1991 para 2000, pode estar associado a eventos migratórios, fato que requer melhor investigação.

Figura 7 - Saldo migratório da população que se autodeclarou indígena, utilizando a informação de lugar de nascimento, segundo as Unidades da Federação. Brasil - 2000

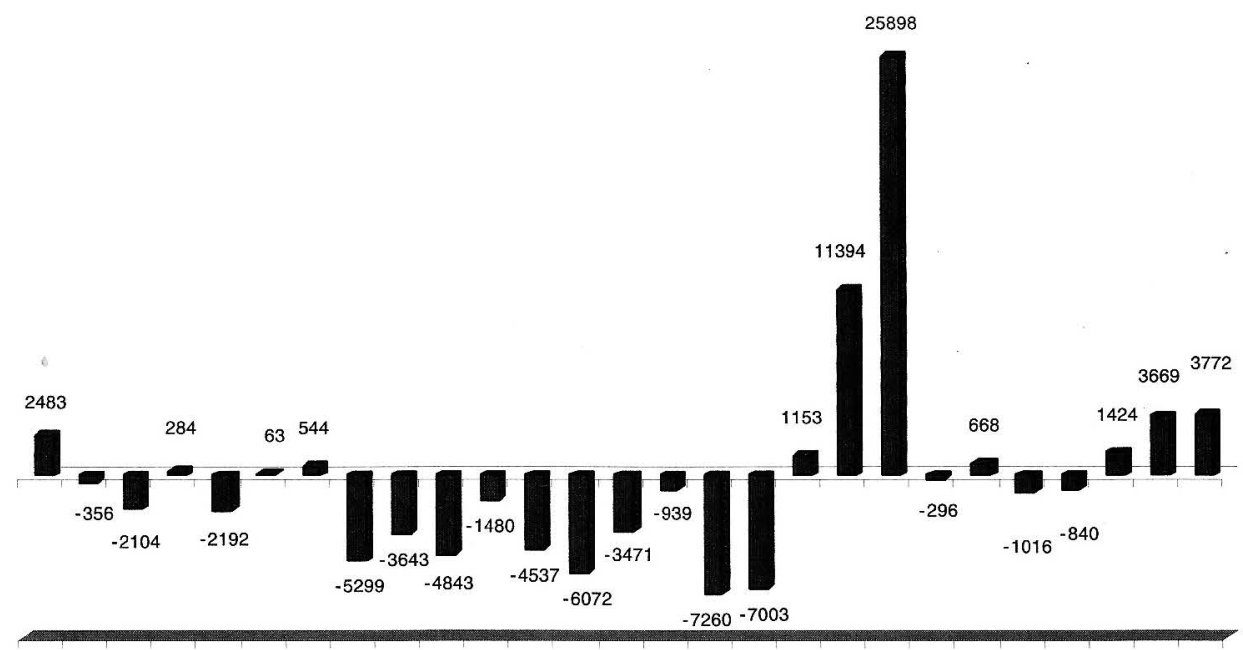

RO AC AM RR PA AP TO MA PI CE RN PB PE AL SE BA MG ES RJ SP PR SC RS MS MT GO DF

\section{Características sociais e econômicas}

O contingente de 'indígenas' apresentou mudanças em termos educacionais na última década. A taxa de alfabetização ${ }^{2}$ dos 'indígenas' era de 49,2\% segundo o Censo Demográfico de 1991 (75,2\% na área urbana e 37,6\% na área rural), aumentando para 73,9\% segundo o Censo Demográfico de 2000 (86,2\% na área urbana e 54,5\% na área rural). Por conseguinte, a taxa de analfabetismo permanece alta nas áreas rurais, embora tenha diminuído no período. Porém, isso não reflete uma melhora ou piora das condições de vida, uma vez que, como já foi mencionado anteriormente, a população 'indígena' rural pertence aos povos habitantes das Terras Indígenas, è seria necessária uma análise antropológica para considerar a escolarização como um indicador de melhoria das condições de vida desta população.

A taxa de escolarização ${ }^{3}$ dos 'indígenas' de 5 a 24 anos de idade revelada pelo Censo Demográfico de 2000 foi 43,8\%, com um crescimento significativo em relação a 1991 (29,6\%). Para as crianças de cinco a nove anos de idade, a taxa alcançou $60,4 \%$ (83,6\% para a área urbana e de apenas $49,2 \%$ para a área rural) (Figuras 8 e 9). Para este subgrupo, a taxa de escolarização em 2000 dobrou em 
relação a 1991. Com relação ao grupo de 10 a 14 anos de idade, observou-se que os 'indígenas' atingiram proporções superiores a $80 \%$.

Figura 8 - Taxa de escolarização das pessoas que se autodeclaram indígenas de 5 a 24 anos de idade, segundo os grupos de idade. Brasil 1991-2000

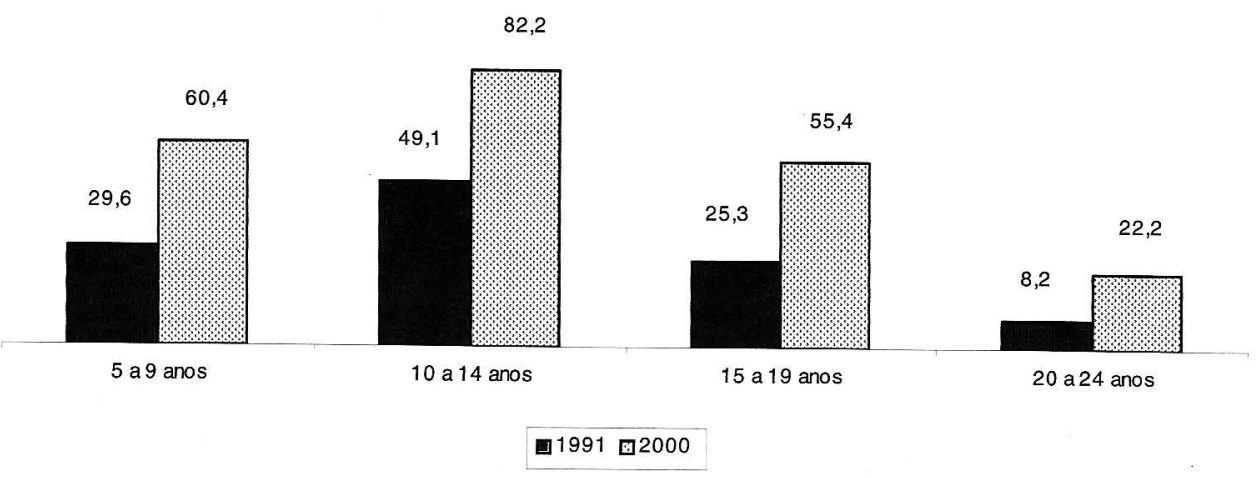

Figura 9 - Taxa de escolarização das pessoas que se autodeclaram indígenas de 5 a 24 anos de idade por situação do domicílio, segundo os grupos de idade. Brasil - 2000

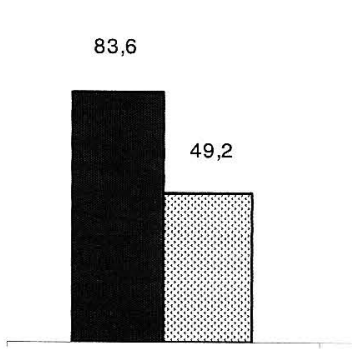

5 a 9 anos
94,2

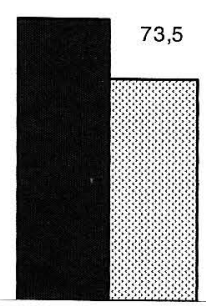

10 a 14 anos
66,2

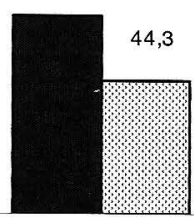

15 a 19 anos

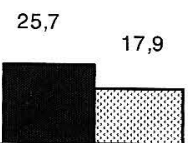

20 a 24 anos

๑Urbana ㅁoral

Os avanços na média de escolaridade dos 'indígenas' foram significativos na última década, com um incremento de 95,8\%. Em 1991, os 'indígenas' de 10 anos ou mais de idade detinham uma média de 2,0 anos de estudo, passando para 3,9 anos em 2000. No período 1991-2000, a área urbana aumentou de 4,0 para 5,0 anos de estudo em média, tendo o maior aumento ocorrido na área rural (de 1,2 para 2,0 anos de estudo) (Figura 10). 
Figura 10 - Média de anos de estudo das pessoas que se autodeclaram indígenas de 10 anos ou mais de idade por situação do domicílio, segundo os grupos de idade. Brasil - 2000

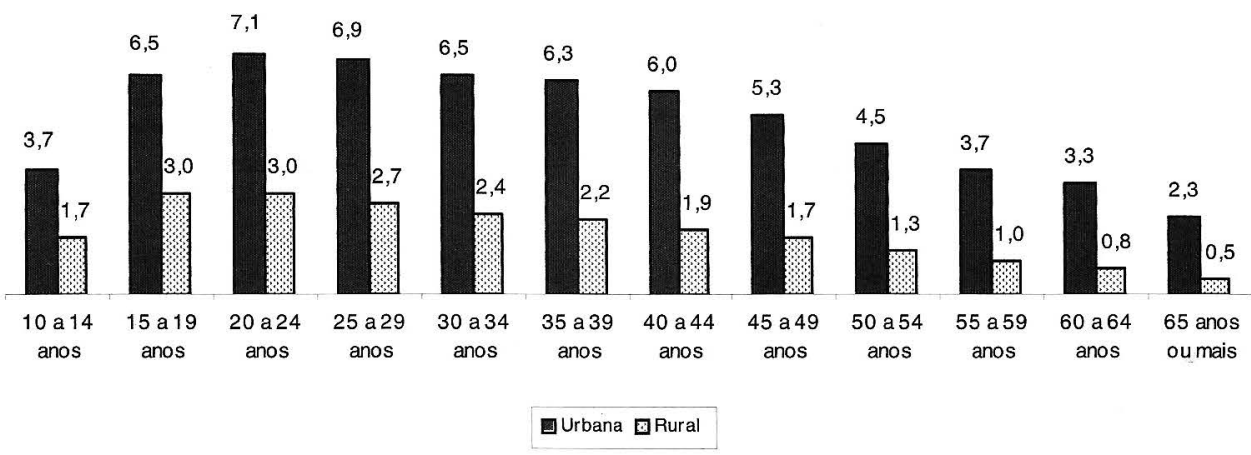

Considerações no âmbito geográfico

As características demográficas, sociais e econômicas dos 'indígenas' são distintas quando analisadas pela localização geográfica. Em 2000, a região Norte detinha o maior percentual, com 1,6\% de 'indígenas' em relação à população total da região. Os estados de Roraima e Amazonas contabilizaram 8,7\% e 4,0\%, respectivamente, que correspondem às proporções mais elevadas de 'indígenas' dentre os estados brasileiros. A região Sudeste detinha a menor proporção.

Figura 11 - Taxa de urbanização da população total e taxa de analfabetismo das pessoas que se autodeclaram indígenas de 15 anos ou mais de idade, segundo as Unidades da Federação. Brasil -2000

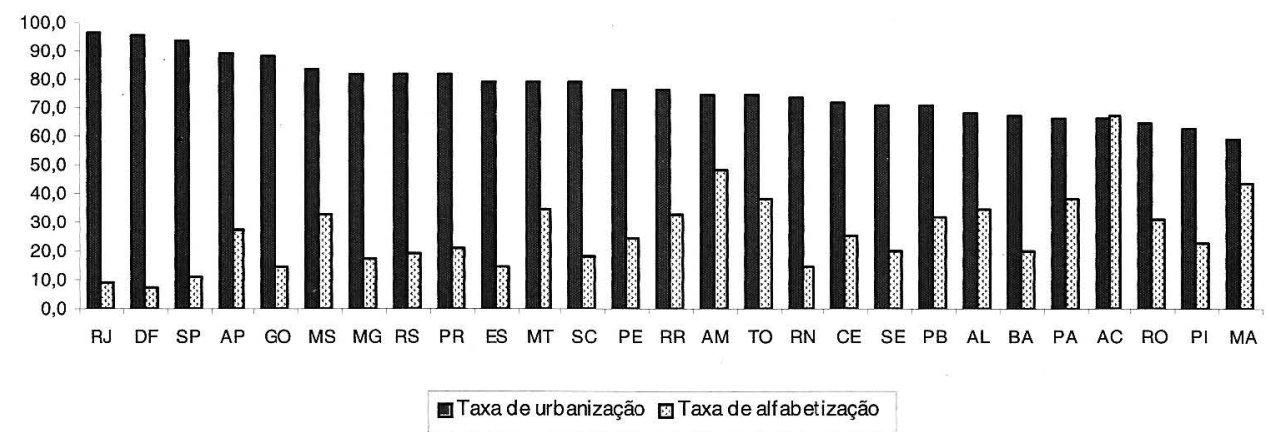


Quanto ao nível educacional, 43,2\% dos 'indígenas' de 15 anos ou mais são analfabetos segundo o Censo Demográfico de 2000 (Figura 11). O Acre apresenta a maior proporção $(66,9 \%)$ dentre todos os estados. Os níveis de analfabetismo de um modo geral são bem elevados, independentemente de localização geográfica, com raras exceções, como Distrito Federal $(7,0 \%)$ e Rio de Janeiro $(9,4 \%)$. Esses são os estados com a maior proporção de população urbana do país. No Brasil, verificase que, quanto maior é a proporção de população urbana, menor a taxa de analfabetismo, o que aponta para uma correlação entre alfabetização e urbanização.

\section{Considerações finais}

A comparação entre os Censos Demográficos de 1991 e 2000 impõe desafios interpretativos de grande magnitude no tocante aos indivíduos que se autodeclararam 'indígenas'. Como vimos nesse trabalho, os totais de 'indígenas' foram de, respectivamente, 294 e 734 mil, vale dizer, um crescimento de mais de $100 \%$ em menos de uma década. As razões que explicam o notável incremento são desconhecidas e demandarão um intenso esforço de análise nos próximos anos. Azevedo G Ricardo (2002) sugerem várias possibilidades como, por exemplo, crescimento demográfico real dos povos indígenas, aumento da proporção de índios urbanizados que optaram pela identificação 'indígena' e que se classificaram como 'pardos' em censos anteriores e ampliação do contingente de pessoas que se classificaram genericamente como 'indígenas', ainda que não se identificando com etnias específicas.

A despeito das dificuldades interpretativas relativas à comparação entre os censos, mediante as informações do Censo Demográfico 2000 surgem caracterizações relevantes sobre os 'indígenas'. Assim, apresentam um perfil demográfico que os diferenciam da população brasileira em geral, como, por exemplo, no que se relaciona à distribuição rural-urbano, composição etária, padrões de fecundidade e escolarização. Além disso, há marcantes diferenças entre os 'indígenas' quanto à situação do domicílio, com aqueles residentes em áreas rurais apresentando características como composição etária predominantemente jovem, elevados níveis de fecundidade e características socioeconômicas diversas (baixos níveis de escolaridade) mais próximas daquele perfil delineado em pesquisas realizadas em comunidades indígenas específicas (Early G Peters, 1990; Azevedo, 2000; Souza G Santos, 2001; Coimbra Jr. et al., 2002; Pagliaro, 2002; ver também Pagliaro, Santos et al., Teixeira e Azevedo, neste volume).

A opinião de muitos especialistas é que a formulação do quesito sobre raça ou cor em censos futuros a serem realizados no Brasil precisa de ser aperfeiçoada. Em alguns países da América Latina, além da autodeclaração, outros critérios são utilizados para a classificação, tais como o idioma ou língua falada e a localização 
geográfica (ver McSweeney G Arps, 2005). Nos censos brasileiros, predomina um conceito de 'índio genérico', haja vista que não são colocadas à disposição informações sobre grupos étnicos específicos (Xavánte, Kayapó, Yanomami etc.). Há pelo menos duas possibilidades a serem implementadas no futuro. Uma primeira seria o refinamento do quesito cor ou raça nos censos nacionais no que tange aos 'indígenas', incorporando critérios como aqueles que têm sido utilizados em outros países. Uma segunda seria a realização de levantamento de população, em escala nacional, estritamente voltado para os povos indígenas, por intermédio do qual informações com um maior grau de detalhamento poderiam ser coletadas.

\section{Agradecimentos}

A técnica Luciana Martins Gomes participou da geração das informações, utilizando o software Redatam.

1 A palavra 'indígena' neste trabalho identifica as pessoas que se autodeclararam como tal nos censos demográficos, independentemente de serem pertencentes a um povo específico ou não.

2 Por taxa de alfabetização entende-se a porcentagem de pessoas alfabetizadas de um grupo etário em relação ao total de pessoas do mesmo grupo etário. Para fins do Censo Demográfico, "pessoa alfabetizada" é aquela capaz de ler e escrever pelo menos um bilhete simples.

3 Por taxa de escolarização entende-se a porcentagem de pessoas de uma determinada faixa etária que freqüenta escola em relação ao total de pessoas da mesma faixa etária.

Referências Bibliográficas

AZEVEDO, M. Censos demográficos e "os índios": dificuldades para reconhecer e contar. In: RICARDO, C. A. (Org.) Povos Indígenas no Brasil 1996/2000. São Paulo: Instituto Socioambiental, 2000. p.79-83.

AZEVEDO, M. M. G RICARDO, F. Censo 2000 do IBGE Revela Contingente "Indígena" Pouco Conhecido. http://www.socioambiental.org, acessado em 14 de abril de 2005. 
COIMBRA Jr., C. E. A. et al. The Xavánte in Transition: health, ecology and bioanthropology in Central Brazil. Ann Arbor: University of Michigan Press, 2002.

EARLY, J. D. G PETERS, J. F. The Population Dynamics of the Mucajaí Yanomama. New York: Academic Press, 1990.

IBGE (INSTITUTO BRASILEIRO DE GEOGRAFIA E ESTATÍSTICA) Censo Demográfico 1991: Manual do Recenseador (CD-ROM - 1.09). Rio de Janeiro: IBGE, 1991.

IBGE (INSTITUTO BRASILEIRO DE GEOGRAFIA E ESTATÍSTICA) Censo Demográfico 2000: Manual do Recenseador (CD-ROM - 1.09). Rio de Janeiro: IBGE, 2000.

IBGE (INSTITUTO BRASILEIRO DE GEOGRAFIA E ESTATÍSTICA) Censo Demográfico 2000: Metodologia do Censo Demográfico 2000. Série Relatórios Metodológicos, vol. 25. Rio de Janeiro: IBGE, 2003.

McSWEENEY, K. G ARPS, S. A "demographic turnaround": the rapid growth of indigenous populations in lowland Latin America. Latin American Research Review, 40:3-29, 2005.

PAGLIARO, H. A Revolução Demográfica dos Povos Indígenas: a experiência dos Kaiabi do Parque Indígena do Xingu, Mato Grosso (1970-1999), 2002. Tese de Doutorado, São Paulo: Faculdade de Saúde Pública, Universidade de São Paulo.

RICARDO, C. A. A sociodiversidade nativa contemporânea no Brasil. In: RICARDO, C. A. (Org.) Povos Indígenas no Brasil 1991/1995. São Paulo: Instituto Socioambiental, 1996. p.i-xii.

SANTOS, R. V. G COIMBRA Jr., C. E. A. Cenários e tendências da saúde e da epidemiologia dos povos indígenas no Brasil. In: COIMBRA Jr., C. E. A., SANTOS, R. V. G ESCOBAR, A. L. (Orgs.) Epidemiologia e Saúde dos Povos Indígenas no Brasil . Rio de Janeiro: Ed. Fiocruz/Associação Brasileira de Saúde Coletiva - Abrasco, 2003. p.13-47.

SILVA, M. F. A demografia e os povos indígenas no Brasil. Revista Brasileira de Estudos de População, 11:261-264, 1994.

SOUZA, L. G. G SANTOS, R. V. Perfil demográfico da população indígena Xavánte de Sangradouro - Volta Grande, Mato Grosso (1993-1997), Brasil. Cadernos de Saúde Pública, 17:355-366, 2001. 